\title{
Daya Tumbuh Bibit Jeruk Keprok Perbanyakan Okulasi Menggunakan Jenis Batang Bawah dan Mata Tempel yang Berbeda
}

\begin{abstract}
Korespondensi: jenalmutakinm@gmail.com

Abstract. Cultivation of tangerines in general uses seeds from the propagation of grafting methods. Grafting is one of the major propagations to improve the quality of seedlings by attaching the buds as the upper stem on a slice of another tree bark as a rootstock, so that they grow unitedly into new plants. This study aimed to determine the growth of tangerine seedlings from grafting propagation system using different rootstock and buds. The experiment was conducted from August to October 2018 in Karangpawitan District, Garut Regency, West Java. The experiment used a Split Plot Design with 5 replications. The main plot is the rootstock $(B)$, namely: b1 $=R L($ Rough Lemon) and b2 = JC (Japanese Citroen). The subplot is the buds $(M)$ namely: $m 1=$ Garut $1, m 2=$ Terigas, $m 3=$ Madura, $m 4=$ Batu 55, and $m 5=$ Tejakula. The results showed no interaction between the treatment of rootstock and resource of buds on the growth of grafted tangerines seedlings, but there was a significant difference independently. JC (Japanese Citroen) rootstock has the best effect on plant height at 60 DAP, while Terigas, Madura, Batu 55, Tejakula buds have the best effect on growth percentage whereas the other parameters of rootstock and resource of buds had no significant effect.
\end{abstract}

\author{
Jenal Mutakin \\ Program Studi Agroteknologi, Fakultas Pertanian, Universitas Garut. Jl Raya Samarang No. \\ 52A Hampor - Tarogong Garut 44151, Indonesia
}

Keywords: Buds, grafting, rootstock, tangerines

\begin{abstract}
Abstrak. Budidaya jeruk keprok pada umumnya menggunakan bibit yang berasal dari perbanyakan cara okulasi. Okulasi adalah salah satu perbanyakan untuk meningkatkan mutu bibit dengan cara menempelkan mata tunas sebagai batang atas pada suatu irisan kulit pohon lain sebagai batang bawah, sehingga tumbuh bersatu menjadi tanaman baru. Penelitian ini bertujuan untuk mengetahui daya tumbuh bibit jeruk hasil sistem perbanyakan okulasi dengan menggunakan batang bawah dan mata tempel yang berbeda. Percobaan dilaksanakan mulai Agustus sampai dengan Oktober 2018 di Kecamatan Karangpawitan Kabupaten Garut Jawa Barat. Metode yang digunakan adalah metode eksperimental dengan menggunakan Rancangan Petak Terpisah (Split Plot) dengan 5 ulangan. Petak utama adalah batang bawah (B) yaitu: $b_{1}=\mathrm{RL}$ (Rough Lemon), $\mathrm{b}_{2}=\mathrm{JC}$ (Japanese Citroen). Anak petak adalah mata tempel $(\mathrm{M})$ yaitu: $\mathrm{m}_{1}=$ Garut $1, \mathrm{~m}_{2}=$ Terigas, $\mathrm{m}_{3}=$ Madura, $\mathrm{m}_{4}=$ Batu 55, dan $\mathrm{m} 5=$ Tejakula. Hasil penelitian menunjukkan tidak terjadi interaksi antara perlakuan batang bawah dan mata tempel terhadap daya tumbuh bibit jeruk okulasi, namun secara mandiri terjadi perbedaan yang nyata. Batang bawah JC (Japanese Citroen) berpengaruh terbaik terhadap tinggi tanaman pada umur 60 HST dan mata tempel Terigas, Madura, Batu 55, Tejakula berpengaruh terbaik terhadap persentase tumbuh sedangkan pada parameter lainnya perlakuan batang bawah dan mata tempel tidak berpengaruh nyata.
\end{abstract}

Kata-kata Kunci : Batang bawah, jeruk keprok, mata tunas, okulasi 


\section{PENDAHULUAN}

Jeruk merupakan salah satu tanaman buah yang digemari dan banyak dikonsumsi oleh masyarakat Indonesia, hal ini terlihat dari total produksi jeruk di Indonesia menduduki peringkat ke dua tertinggi setelah manggis. Buah jeruk memiliki kandungan gizi yang cukup tinggi, seperti vitamin $\mathrm{C}$ yang berperan sebagai zat antioksidan yang mampu mencegah beberapa penyakit seperti kanker, jantung dan penuaan dini (Wariyah 2010).

Produksi buah jeruk di Indonesia pada tahun 2012, 2013, dan 2014 secara berturut-turut sebesar 1498, 1548, dan 1785 juta ton. Dari angka-angka tersebut terlihat terdapat peningkatan produksi dari tahun 2012 hingga 2014 secara berturut-turut sebesar 50000 dan 236000 ton. Provinsi Jawa Barat diketahui memproduksi buah jeruk sebanyak 29539 ton pada tahun 2014. Kabupaten Garut merupakan salah satu sentra tanaman jeruk di Provinsi Jawa Barat. Beberapa kecamatan penghasil jeruk di kabupaten Garut antara lain: Cikajang, Cisurupan, Pakenjeng, Samarang, Bayongbong, Cigedug, Sukaresmi, Pasirwangi, Karangpawitan, Wanaraja, Sucinaraja, Pangatikan dan Malangbong (BPS 2015).

Budidaya Jeruk secara komersial umumnya menggunakan bibit yang berasal dari okulasi (Samson 1980). Keunggulan bibit dari okulasi diantaranya mempunyai perakaran yang kuat, tahan terhadap hama dan penyakit, tahan kekeringan dan kelebihan air serta memperoleh suatu tanaman sesuai dengan yang diinginkan. Salah satu kelemahannya adalah seringkali terjadi ketidak serasian antara batang atas dan batang bawah (Pracaya 2001). Menyatunya antara batang bawah dan batang atas (entres) dapat terjadi jika pada letak penempelan melakukan aktivitas pembelahan kambium dan cukup kandungan hara (Rahmatika \& Setyawan 2018).

Kendala yang dihadapi pada okulasi adalah inkompatibilitas batang bawah dan batang atas atau yang disebut mata tempel. Inkompatibilitas antara batang bawah dan batang atas sering terjadi karena kelainan anatomi jaringan vaskular di jaringan kalus (Errea et al. 2001). Batang atas atau entres adalah calon bagian atas atau tajuk tanaman yang di kemudian hari akan menghasilkan buah berkualitas unggul. Batang atas dapat berupa mata tunas tunggal yang digunakan dalam teknik okulasi ataupun berupa ranting dengan lebih dari satu mata tunas atau ranting dengan tunas pucuk yang digunakan dalam sambungan (grafting). Entres inilah yang disambungkan pada batang bawah untuk menggabungkan sifat-sifat yang unggul dalam satu bibit tanaman. Entres sebagai batang atas harus diambil dari pohon induk yang sudah diketahui betul sifat unggulnya (Prastowo et al. 2006).

Batang bawah memiliki kemampuan beradaptasi dengan kondisi lingkungan yang kurang menguntungkan antara lain; kekeringan, kelebihan air, dan serangan hama dan penyakit tertentu. Batang bawah sangat menentukan pertumbuhan batang atas tanaman (Devy \& Jati 2008). Batang bawah yang digunakan untuk okulasi pada umumnya adalah Rough Lemon (Ali \& Mirza 2006) dan jenis jeruk lokal Japanese Citroen (Wahyudi et al. 2018). Batang bawah Rough Lemon dan Japanese Citroen memiliki banyak keunggulan, salah satunya adalah kecocokan antara batang bawah dan batang atas, sehingga memberikan pengaruh positif terhadap kelangsungan hidup tanaman dan produktivitasnya, karena itu jenis jeruk tersebut banyak digunakan di Indonesia (Hodijah 2012, Poerwanto et al. 2002). Penelitian ini bertujuan untuk mengetahui daya tumbuh bibit jeruk sistem perbanyakan okulasi pada batang bawah dan mata tempel yang berbeda.

\section{BAHAN DAN METODE PENELITIAN}

Percobaan dilakukan Kecamatan Karangpawitan Kabupaten Garut dengan ketinggian tempat 758 meter diatas permukaan laut (m dpl) pada bulan Agustus sampai November 2018. Berdasarkan kriteria Schmidt \& Ferguson (1951), daerah tersebut memiliki tipe curah hujan C.

Bahan yang digunakan adalah bibit jeruk sebagai batang bawah yaitu Rough Lemon (RL) dan Japanese Citroen (JC) yang sudah berumur 7 bulan yang didapatkan dari penangkar bibit jeruk di Karangpawitan, dan batang atas (entres) yaitu Garut 1, Terigas, Madura, Batu 55, dan Tejakula yang didapatkan dari Balai Benih Hortikultura Kecamatan Cisurupan, pupuk NPK, urin kelinci, pestisida dan air. Batang bawah yang digunakan untuk okulasi telah berumur 7 bulan, berdiameter $0,5 \mathrm{~cm}$ 
dengan tinggi mencapai $30 \mathrm{~cm}$. Mata tunas (entres) diambil dari pohon induk dalam kondisi sehat dan bebas dari hama dan penyakit.

Alat yang digunakan dalam penelitian ini antara lain: pisau okulasi (tikel), sarung tangan, sepatu boots, plastik pembungkus (ukuran $0.3 \mathrm{~mm}$ dengan lebar $15 \mathrm{~cm}$ dan panjang $17 \mathrm{~cm}$ ), tali, jangka sorong, kertas, gunting, timbangan analitik, kertas mika, boardmarker, dan gunting okulasi/grafting.

Metode yang digunakan adalah metode eksperimental dengan menggunakan Rancangan Petak Terpisah (Split Plot) dengan 10 perlakuan dan 5 ulangan. Petak utama adalah batang bawah (B) dengan 2 taraf perlakuan dan anak petak adalah mata tempel (M) dengan 5 taraf perlakuan. Petak utama yaitu yaitu: $b_{1}=$ RL (Rough Lemon), $b_{2}=$ JC (Japanese Citroen). Anak petak yaitu: $\mathrm{m}_{1}=$ Garut $1, \mathrm{~m}_{2}=$ Terigas, $\mathrm{m}_{3}=$ Madura, $\mathrm{m}_{4}=$ Batu 55 , dan $\mathrm{m}_{5}=$ Tejakula. Parameter yang diamati meliputi persentase tumbuh, waktu pecah tunas, dan tinggi tunas. Data yang diperoleh kemudian dianalisis menggunakan uji ANOVA dengan model linier (Gasperzs 2006), menggunakan Microsoft Excel 2010.

\section{HASIL DAN PEMBAHASAN}

\section{Persentase Tumbuh}

Berdasarkan hasil analisis statistik, persentase tumbuh tidak dipengaruhi oleh interaksi perlakuan antara batang bawah dan mata tempel. Analisis rata-rata persentase tumbuh dapat dilihat pada Tabel 1.

Tabel 1. Persentase tumbuh bibit jeruk hasil okulasi menggunakan batang bawah dan mata tempel yang berbeda $(\%)$

\begin{tabular}{lc}
\hline \multicolumn{1}{c}{ Perlakuan } & Persentase Tumbuh $(\%)$ \\
\hline Batang bawah (B) & \\
$\mathrm{b}_{1}$ (Rough Lemon) & 98.00 \\
$\mathrm{~b}_{2}$ (Japanese Citroen) & 92.00 \\
\hline Mata Tempel (M) & \\
$\mathrm{m}_{1}$ (Garut 1) & $80.00^{\mathrm{a}}$ \\
$\mathrm{m}_{2}$ (Terigas) & $100.00^{\mathrm{b}}$ \\
$\mathrm{m}_{3}$ (Madura) & $100.00^{\mathrm{b}}$ \\
$\mathrm{m}_{4}$ (Batu 55) & $100.00^{\mathrm{b}}$ \\
$\mathrm{m}_{5}$ (Tejakula) & $100.00^{\mathrm{b}}$ \\
\hline Keterangan: Angka rata-rata pada kolom yang ditandai dengan huruf yang berbeda menunjukkan berbeda nyata pada taraf \\
5\%
\end{tabular}

Tabel 1 menunjukkan bahwa perlakuan batang bawah yang berbeda tidak berpengaruh nyata terhadap presentase tumbuh bibit jeruk hasil okulasi dengan mata tempel yang berbeda. Keadaan ini menggambarkan kedua jenis batang bawah memiliki kemampuan tumbuh yang sama dan memberikan hasil yang baik terhadap persentase tumbuh tanaman yaitu lebih dari 90\%. Hal ini disebabkan batang bawah yang dipakai memiliki kulit yang rata dan cukup mudah untuk dilakukan pembukaan saat akan menempelkan mata tempel sehingga memudahkan proses penempelan dan terjadi kompabilitas yang baik pada keduanya. Perlakuan mata tempel menunjukkan perbedaan nyata antara batang bawah dan mata tempel terhadap persentase tumbuh tanaman. Mata Tempel Garut 1 memiliki rata-rata terendah yang berbeda nyata dibandingkan dengan perlakuan lainnya. Hal ini diduga mata tempel jeruk garut $\left(\mathrm{m}_{1}\right)$ memiliki kompatibilitas yang lebih rendah dibandingkan dengan mata tempel jeruk keprok lainnya. Keberhasilan okulasi (penempelan) memerlukan kompatibilitas antara batang atas dan batang bawah, serta kemampuan batang atas (mata tempel) itu sendiri untuk pecah dan tumbuh (Musthofa et al. 2019).

\section{Waktu Pecah Tunas}

Kombinasi perlakuan batang bawah dan mata tempel tidak berpengaruh nyata terhadap waktu pecah tunas, baik secara mandiri maupun interaksinya. Hasil analisis rata-rata waktu pecah tunas disajikan pada Tabel 2. 
Tabel 2. Waktu Pecah Tunas bibit jeruk hasil okulasi menggunakan batang bawah dan mata tempel yang berbeda (hari)

\begin{tabular}{lc}
\hline Perlakuan & Waktu pecah tunas (hari) \\
\hline Batang bawah (B) & \\
$\mathrm{b}_{1}$ (Rough Lemon) & 15.36 \\
$\mathrm{~b}_{2}$ (Japanese Citroen) & 16.36 \\
\hline Batang Atas (M) & 15.00 \\
$\mathrm{~m}_{1}$ (Garut 1) & 17.50 \\
$\mathrm{~m}_{2}$ (Terigas) & 17.90 \\
$\mathrm{~m}_{3}$ (Madura) & 16.70 \\
$\mathrm{~m}_{4}$ (Batu 55) & 12.20 \\
$\mathrm{~m}_{5}$ (Tejakula) & \\
\hline
\end{tabular}

Keterangan: Angka rata-rata pada kolom yang ditandai dengan huruf yang berbeda menunjukkan berbeda nyata pada taraf $5 \%$

Tabel 2 menunjukkan bahwa tidak terjadi perbedaan yang nyata baik pada perlakuan batang bawah maupun batang atas terhadap waktu pecah tunas. Hal ini diduga karena kemampuan batang bawah jeruk dalam membentuk kalus dan hormon yang berada pada kedua jenis batang bawah seragam sehingga pada saat pecah tunas memiliki umur yang seragam. Kemampuan batang jeruk dalam membentuk kalus dan tunas yang sama diduga karena umur dari batang bawah yang sama sehingga kemampuan pembentukan kalus menjadi sama. Menurut Sutami et al. (2009) menyatakan bahwa perbedaan tingkat kecepatan mata tunas pecah diduga karena kemampuan tanaman yang berbeda untuk membentuk pertautan okulasi yang berhubungan dengan jumlah dan kecepatan pembentukan kalus.

Faktor mata tempel tidak berpengaruh nyata terhadap waktu pecah tunasdiduga umur mata tempel relatif muda dan hormon yang terkandung pada mata tempel relatif seragam, sehingga menghasilkan kalus yang sama cepat, akibatnya pecahnya mata tempel pada berbagai taraf perlakuan menjadi tidak berbeda nyata. Pecahnya mata tunas terjadi karena proses fisiologis pada tanaman. Salah satu faktor yang mendorong pecahnya mata tunas ialah adanya hormon endogen pada tanaman. Keseimbangan antara asam absisat dan sitokinin membantu mengendalikan pecahnya mata tunas lateral. Pada konsentrasi asam absisik yang mulai menurun dan sitokinin yang meningkat, maka mata tunas tananam akan pecah (Wardaningsih et al. 2004). Dieleman et al. (1998) membuktikan bahwa batang bawah durian yang berumur lebih muda mempunyai respons yang cepat untuk mendorong pecahnya mata tunas karena batang bawah yang lebih muda sel-selnya dalam keadaan aktif membelah (Bansir 2011).

\section{Tinggi Tunas}

Kombinasi perlakuan batang bawah dan mata tunas tidak terjadi perbedaan yang nyata terhadap tinggi tunas pada umur 70 dan 80 HST baik secara madiri maupun interaksinya, namun umur 60 HST secara mandiri perlakuan batang bawah menunjukkan perbedaan yang nyata. Hasil analisis rata-rata tinggi tunas disajikan pada Tabel 3.

Dari Tabel 3 dapat dilihat rata-rata tinggi tunas pada perlakuan batang bawah menunjukkan berbeda nyata pada umur 60 HST, namun pada umur 70 dan 80 HST tidak menunjukkan berbeda nyata. Keadaan ini diduga JC (b2) lebih toleran terhadap kekurangan air pada saat penelitian yang dilakukan pada musim kemarau, karena itu pada 60 HST perlakuan (b2) tunas menjadi lebih tinggi dibandingkan b1. Hal ini sejalan dengan hasil penelitian Budiyati et al. (2010) tinggi tanaman jeruk keprok SoE yang diokulasi pada batang bawah JC terlihat berbeda nyata lebih tinggi dibanding mata tempel yang ditempelkan pada batang bawah RL pada parameter tinggi tanaman. Menurut Supriyanto \& Setiono (2006) Batang bawah JC paling disukai karena daya adaptasinya luas, mempunyai kompatibilitas yang tinggi, tahan kekeringan dan salinitas tinggi, tetapi peka terhadap penyakit CVPD, CTV, CEV, penyakit busuk akar, dan batang. Pada umur 70 dan 80 HST batang bawah jeruk RL terus mengalami pertumbuhan yang tidak berbeda nyata dengan JC karena perakarannya sudah menjadi semakin banyak sehingga pada umur 70 dan 80 HST taraf perlakuan batang bawah menjadi tidak 
berbeda nyata. Menurut Devy \& Jati (2008) Batang bawah dari jenis rough lemon (RL) memiliki keistimewaan perakaran yang baik untuk tanah berbatu dan kurang subur. Sehingga pada saat tanaman sudah berumur 70 dan 80 HST menjadi tidak berbeda nyata.

Tabel 3. Tinggi Tunas bibit jeruk hasil okulasi menggunakan batang bawah dan mata tempel yang berbeda $(\mathrm{cm})$

\begin{tabular}{lccc}
\hline Perlakuan & \multicolumn{3}{c}{ Tinggi tunas $(\mathbf{c m})$} \\
\cline { 2 - 4 } Batang bawah (B) & 60 HST & 70 HST & 80 HST \\
b $_{1}$ (Rough Lemon) & $14.88^{\mathrm{a}}$ & $21.12^{\mathrm{a}}$ & $25.28^{\mathrm{a}}$ \\
$\mathrm{b}_{2}$ (Japanese Citroen) & $18.80^{\mathrm{b}}$ & $26.44^{\mathrm{a}}$ & $36.96^{\mathrm{a}}$ \\
\hline Batang Atas (M) & & & \\
$\mathrm{m}_{1}$ (Garut 1) & $19.80^{\mathrm{a}}$ & $24.40^{\mathrm{a}}$ & $28.50^{\mathrm{a}}$ \\
$\mathrm{m}_{2}$ (Terigas) & $15.20^{\mathrm{a}}$ & $23.10^{\mathrm{a}}$ & $27.60^{\mathrm{a}}$ \\
$\mathrm{m}_{3}$ (Madura) & $18.80^{\mathrm{a}}$ & $26.50^{\mathrm{a}}$ & $30.80^{\mathrm{a}}$ \\
$\mathrm{m}_{4}$ (Batu 55) & $15.40^{\mathrm{a}}$ & $22.30^{\mathrm{a}}$ & $26.90^{\mathrm{a}}$ \\
$\mathrm{m}_{5}$ (Tejakula) & $15.00^{\mathrm{a}}$ & $22.60^{\mathrm{a}}$ & $26.80^{\mathrm{a}}$ \\
\hline $\mathrm{K}^{\mathrm{a}}$ & & &
\end{tabular}

Keterangan: Angka rata-rata pada kolom yang ditandai dengan huruf yang berbeda menunjukkan berbeda nyata pada taraf $5 \%$

Perlakukan mata tempel menunjukkan tidak berbeda nyata terhadap tinggi tanaman pada umur 60, 70 dan, 80 HST. Hal ini diduga pertumbuhan genetik pada fase awal pertumbuhan tanaman jeruk pada varietas $m_{1}, m_{2}, m_{3}, m_{4}$, dan $m_{5}$ seragam sehingga pertumbuhan mata tempel menjadi tidak berbeda nyata. Menurut Suharsi \& Sari (2013) kecukupan cadangan makanan dalam batang bawah juga berpengaruh pada pertumbuhan tunas okulasi yang dihasilkan. Faktor cadangan makanan pada mediapun memiliki bagian dalam mempengaruhi tinggi tanaman.

\section{SIMPULAN}

1. Tidak terjadi interaksi antara berbagai berbagai jenis batang bawah dan mata tempel terhadap daya tumbuh bibit jeruk okulasi.

2. Batang bawah dan mata tempel berpengaruh nyata terhadap persentase tumbuh. Perlakuan batang bawah $b_{2}$ (Japanese Citroen) memberikan nilai rata-rata terbaik terhadap tinggi tunas. Perlakuan mata tempel $m_{2}$ (Terigas), $m_{3}$ (Madura), $m_{4}$ (Batu 55) dan $m_{5}$ (Tejakula) memberikan nilai ratarata persentase tumbuh yang lebih tinggi dibandingkan dengan mata tempel Garut.

\section{DAFTAR PUSTAKA}

Ali S, B Mirza. 2006. Micropropagation of rough lemon (Citrus jambhiri Lush.): Effect of explant type and hormone concentration. Acta Bot. Croat. 65(2):137-146.

[BPS] Badan Pusat Statistik. 2015. Produktivitas Buah Jeruk Nasional. https://www.bps.go.id/site. Diakses Tanggal 22 April 2018.

Bansir L. 2011. Pengembangan Potensi Durian (Durio zibethinus L.) Lokal: Eksplorasi, Identifikasi, Persilangan dan Perbanyakan Vegetatif. Disertasi. Program Pascasarjana Universitas Brawijaya. Malang.

Budiyati E, Hardiyanto, H Ashari. 2013. Potensi Pembenihan Jeruk Lokal Komersial Varietas Keprok SoE pada Tiga Varietas Batang Bawah (JC, RL dan Volkameriana). Balai Penelitian Tanaman Jeruk dan Buah Subtropika Pusat Penelitian dan Pengembangan Hortikultura Badan Penelitian dan Pengembangan Pertanian Kementerian Pertanian.

Devy NF, Jati. 2008. Perbanyakan 13 Jenis Batang Bawah serta 5 Jenis Jeruk Asal Pasang Surut Secara In Vitro. Prosiding Seminar Nasional Jeruk 2007. Pusat Penelitian dan Pengembangan Hortikultura, Badan Penelitian dan Pengembangan Pertanian. Malang. Hal 168 - 180.

Dieleman JA, FWA Verstappen, D Kuiper. 1998. Bud Break and Cytokinin Concentration in Bleeding Sap of Rosa Hybrida as Affected by the Genotype of the Rootstock. J. Plant Physiol. 154: 46872 . 
Errea P, L Garay, JA Marı'n. 2001. Early Detection of Graft Incompatibility In Apricot (Prunus armeniaca) Using In Vitro Techniques. Jurnal Physiologia Plantarum. 112: 135-141

Gasperz U. 2006. Teknik Analisis dalam Penelitian Percobaan Jilid 1. PT Tarsito. Bandung.

Hodijah S. 2012. Pengaruh Understem terhadap Pertumbuhan Vegetatif Jeruk Besar (citrus grandis (1.) Osbeck) Kultivar Cikoneng. Skripsi. Fakultas Pertanian. Universitas Winaya Mukti.

Musthofa MI, A Sugiyatno, T Wardiyati, M Roviq. 2019. Pengaruh Posisi Mata Tempel Pada Keberhasilan Okulasi Beberapa Varietas Jeruk Keprok (Citrus reticulate). Jurnal Produksi Tanaman. 7(5):867 - 873.

Poerwanto R, S Susanto, SS Harjadi. 2002. Pengembangan Jeruk Unggulan di Indonesia. Dalam Makalah Semiloka Nasional Pengembangan Jeruk dan Pameran Jeruk Unggulan. 10-11 Juli 2002. Bogor. 25 hal.

Pracaya. 2001. Jeruk Manis. Penebar Swadaya, Jakarta.

Prastowo N, JM Roshetko. 2006. Teknik Pembibitan dan Perbanyakan Vegetatif Tanaman Buah. World Agroforestry Center: Bogor.

Rahmatika W, F Setyawan. 2018. Kompatibilitas Batang Bawah dengan Batang Atas pada Metode Grafting Tanaman Durian (Durio zibethinus Murr). Agritrop. 16 (2) : 268 - 275.

Samson JA. 1980. Tropical Friuts. Longman Group Limited. New York. 64-99.

Schmidt FH, JHA Ferguson. 1951. Rainfall Types Based On Wet and Dry Period Rations for Indonesia With Western New Guinea. Kementrian Perhubungan Meteorologi dan Geofisika. Jakarta. Setiono. 2014.

Suharsi TK, ADP Sari. 2013. Pertumbuhan Mata Tunas Jeruk Keprok (Citrus nobilis) Hasil Okulasi pada Berbagai Media Tanam dan Umur Batang Bawah Rough Lemon (C. jambhiri). Departemen Agronomi dan Hortikultura, Fakultas Pertanian. Intitut Pertanian Bogor.

Supriyanto A, Setiono. 2006. Evaluasi Keragaan Pertumbuhan Vegetatif 10 Varietas Jeruk Komersial pada Empat Varietas Batang Bawah di Kabupaten Sambas, Kalimantan Barat. Prosiding Seminar Nasional Jeruk Tropika Indonesia. Pusat Penelitian dan Pengembangan Hortikultura. Badan Penelitian dan Pengembangan Pertanian.

Sutami A, Mursyid, GMS Noor. 2009. Pengaruh Umur Batang Bawah dan Panjang Entris Terhadap Keberhasilan Sambungan Bibit Jeruk Siam Banjar Label Biru. Agroscientae. 16(2): 1-9.

Wahyudi E, A Sumadi, Nuraeni. 2018. Keberhasilan Okulasi Beberapa Jenis Batang Bawah Dengan Entres Jeruk Siam Madu (Citrus microcarpa) Yang Berbeda Lama Penyimpanan. Jurnal Agrotek Indonesia 3(2): 89-96.

Wardaningsih DP, A Supriyanto, HYB Suwasono, Sitawati. 2004. Keberhasilan Pembibitan Pamelo (Citrus grandis (L) osbeck) secara Okulasi melalui Penyimpanan Dingin Mata Tempel dan Perlakuan Perompesan Batang Bawah. Prosiding Seminar Jeruk Siam Nasional. Pusat Penelitian dan Pengembangan Hortikultura-Badan Penelitian dan Pengembangan Pertanian.

Wariyah C. 2010. Vitamin C retention and acceptablity of orange (Citrus nobilis Var.microcarpa) juice during storage in refrigerator. J AgriSains. 1(1): 5055.5 